\section{J'TI}

JOURNAL OF

TRAUMA AND INJURY

\title{
Comparison of Penetrating and Blunt Traumatic Diaphragmatic Injuries
}

\author{
Sang Su Lee, M.D. ${ }^{1}$, Sung Youl Hyun, M.D., Ph.D. ${ }^{2}$, Hyuk Jun Yang, M.D., Ph.D. ${ }^{1}$, \\ Yong Su Lim, M.D., Ph.D. ${ }^{1}$, Jin Seong Cho, M.D., Ph.D. ${ }^{1}$, Jae Hyug Woo, M.D. ${ }^{1}$ \\ ${ }^{1}$ Department of Emergency Medicine, Gachon University Gil Medical Center, Gachon \\ University College of Medicine, Incheon, Korea \\ ${ }^{2}$ Department of Traumatology, Gachon University Gil Medical Center, Gachon University \\ College of Medicine, Incheon, Korea
}

Received: September 16, 2019

Revised: October 13, 2019

Accepted: October 29, 2019

\section{Correspondence to}

Sung Youl Hyun, M.D., Ph.D.

Department of Traumatology, Gachon University Gil Medical Center, Gachon University College of Medicine, $21 \mathrm{Nam}-$ dong-daero 774 beon-gil, Namdong-gu, Incheon 21565, Korea

Tel: +82-32-460-3015

Fax: +82-32-460-3019

E-mail: sungyoul@gilhospital.com
Purpose: Traumatic diaphragmatic injury (TDI) is no longer considered to be a rare condition in Korea. This study investigated differences in the prevalence of accompanying injuries and the prognosis in patients with traumatic diaphragmatic damage according to the mechanism of injury.

Methods: We retrospectively reviewed the medical records of patients with TDI who were seen at a regional emergency medical center from January 2000 to December 2018. Among severe trauma patients with traumatic diaphragmatic damage, adults older than 18 years of age with a known mechanism of injury were included in this study. Surgery performed within 6 hours after the injury was sustained was defined as emergency surgery. We assessed the survival rate and likelihood of respiratory compromise according to the mechanism of injury.

Results: In total, 103 patients were analyzed. The patients were categorized according to whether they had experienced a penetrating injury or a blunt injury. Thirty-five patients had sustained a penetrating injury, and traffic accidents were the most common cause of blunt injuries. The location of the injury did not show a statistically significant difference between these groups. Severity of TDI was more common in the blunt injury group than in the penetrating injury group, and was also more likely in patients with respiratory compromise. However, sex, the extent of damage, and the initial Glasgow coma scale score had no significant relationship with severity.

Conclusions: Based on the findings of this study, TDI should be recognized and managed proactively in patients with blunt injury and/or respiratory compromise. Early recognition and implementation of an appropriate management strategy would improve patients' prognosis. Multi-center, prospective studies are needed in the future.

Keywords: Hernia, Diaphragmatic, Traumatic; Wounds, Penetrating; Wounds, Nonpenetrating; Prognosis 


\section{INTRODUCTION}

Traumatic diaphragmatic injury (TDI) is an uncommon condition that occurs in $2 \%$ of all trauma cases. It occurs in $1-7 \%$ of individuals with evident blunt injuries and $10-15 \%$ of those with penetrating injuries. TDI is considered a marker of severe trauma, as it is usually associated with life-threatening damage [1-4]. The mortality rate of TDI is $30 \%$ in individuals with penetrating injuries and $15-45 \%$ in those with blunt injuries. Road traffic accidents are the most common cause of blunt injuries, and rarely cause isolated damage; instead, injuries sustained in traffic accidents are often accompanied by major organ damage. According to the 2012 report of the United States National Trauma Data Bank, 33\% of cases of TDI occurred due to blunt trauma, and the rest occurred due to penetrating injuries [5]. In the most recent 20 years, the number of TDI cases due to blunt injuries has increased due to the increased incidence of car accidents. The mortality rate has also increased due to the high incidence of accompanying injuries in cases of blunt trauma [6]. This study aimed to explore the prevalence of accompanying injuries in patients with TDI, as well as their prognosis, according to the mechanism of injury.

\section{METHODS}

\section{Study patients and study period}

This study retrospectively analyzed the age, sex, cause of trauma, accompanying damage, early vital signs, injury severity score (ISS), revised trauma score (RTS), method of diagnosis, time to diagnosis, area of diaphragmatic injury, surgical approach, size of the diaphragmatic injury, organ herniation, complications, and mortality based on the medical records of severe trauma patients with TDI aged 18 years or above who presented to a single district emergency medical center between January 2000 and December 2018. Only patients with a known mechanism of injury were included; therefore, one patient without a confirmed mechanism of injury was excluded from the analysis. Patients with missing medical records were also excluded from the study.

\section{Study method}

The medical records of the included patients with TDI were retrospectively analyzed. Their early level of consciousness was measured using the Glasgow coma scale (GCS), their status upon presentation was evaluated using the RTS, and the severity of damage was assessed using the ISS, with a cut-off score of 15 used to indicate a severe injury. Information on the mechanism of injury, major area of injury, and organ herniation caused by damage were obtained. The time of diagnosis was determined by identifying the diagnoses before and after surgery. In cases of fatal injuries, the direct cause of death was determined based on the abbreviated injury scale (AIS), but the final decision was made based on the progress report of the treating physician and death report, since severity and AIS scores may not be fully correlated. To evaluate patients' status after presentation, their level of consciousness using the GCS score, their first systolic and diastolic blood pressure upon presentation, heart rate, respiratory rate, body temperature, $\mathrm{pH}$ of arterial blood, blood partial pressure of $\mathrm{CO}_{2}$, bicarbonate level, lactate levels, and base excess were assessed. Data were also gathered on interventions performed, such as endotracheal intubation, chest drain insertion, and nasogastric tube insertion. Endotracheal intubation was stratified based on the reason for intubation, while chest drain insertion was stratified based on the reason for drain insertion and the location of the drain. The surgical approach was categorized as thoracic or abdominal, and surgery performed within 6 hours after the injury was sustained was deemed emergency surgery. In contrast, surgery performed more than 6 hours after the injury was defined as delayed surgery.

\section{Statistical analysis}

SPSS version 25.0 (IBM Corp., Armonk, NY, USA) was used for the analysis of baseline characteristics and the cross-analysis. The chi-square test was used for the univariate analysis. Continuous variables that did not follow a normal distribution were expressed as median values (interquartile range [IR]: 25-75\%), and the Mann-Whitney $U$ test was used to analyze these variables. Logistic regression analysis was used for multivariate analysis, using the backward elimination method. A p-value of less than 0.05 was considered to indicate statistical significance. 


\section{RESULTS}

Of 104 patients with TDI who presented to Gachon University Gil Medical Center during the study period, 103 were enrolled in the study. We excluded one patient who was found unconscious without a definite cause of injury. The patients were categorized according to whether they had experienced a penetrating injury or a blunt injury. The median age was 2.5 years higher in the blunt injury group, but this difference was not statistically significant. The blunt injury group also had a higher proportion of male patients (Table 1). Thirty-five of the 103 patients sustained a stab injury, accounting for all 37 patients who sustained a penetrating injury. Traffic accidents were the

Table 1. Clinical characteristics of patients with TDI

\begin{tabular}{|c|c|c|c|c|}
\hline Variables & Total $(n=103)$ & Penetrating $(n=37)$ & Blunt (n=66) & $p$-value \\
\hline Median age (years) & $56(44-63)$ & $54(44-60)$ & $56.5(44-65)$ & 0.304 \\
\hline Sex (male) & $76(73.8)$ & $23(62.2)$ & $53(80.3)$ & 0.045 \\
\hline Mechanism of injury & & & & $<0.001$ \\
\hline Stab injury & $35(34.0)$ & $35(94.6)$ & $0(0.0)$ & \\
\hline Traffic accident & $43(41.8)$ & $0(0.0)$ & $43(65.2)$ & \\
\hline Fall & 15 (14.6) & $1(2.7)$ & $14(21.2)$ & \\
\hline Slip & $4(3.9)$ & $1(2.7)$ & $3(4.6)$ & \\
\hline Crush injury & $6(5.8)$ & $0(0.0)$ & $6(9.1)$ & \\
\hline Site of injury & & & & 0.469 \\
\hline Right & $32(31.1)$ & $14(37.8)$ & $18(27.3)$ & \\
\hline Left & $69(67.0)$ & $22(59.5)$ & $47(71.2)$ & \\
\hline Bilateral & $2(1.9)$ & $1(2.7)$ & $1(1.5)$ & \\
\hline Median length of Injuries (cm) & $5(3-10)$ & $4(3-4)$ & $7(4-11)$ & $<0.001$ \\
\hline Initial GCS & & & & 0.005 \\
\hline Mild (14-15) & $66(64.1)$ & $31(83.8)$ & $35(53.0)$ & \\
\hline Moderate (9-13) & $16(15.5)$ & $4(10.8)$ & $12(18.2)$ & \\
\hline Severe (3-8) & $21(20.4)$ & $2(5.4)$ & $19(28.8)$ & \\
\hline Median RTS & $6.83(5.97-7.84)$ & $7.40(7.55-7.84)$ & $6.51(5.44-7.84)$ & 0.001 \\
\hline ISS & & & & 0.016 \\
\hline$<15$ & $25(24.3)$ & $14(37.8)$ & $11(16.7)$ & \\
\hline$\geq 15$ & $78(75.7)$ & $23(62.2)$ & $55(83.3)$ & \\
\hline Diagnostic time & & & & 0.200 \\
\hline Preoperative diagnosis & $39(37.9)$ & $10(27.0)$ & $29(43.9)$ & \\
\hline \multicolumn{5}{|l|}{ Delayed diagnosis } \\
\hline Under suspicion & 19 (18.5) & $7(18.9)$ & $12(18.2)$ & \\
\hline Incidental finding & 45 (43.7) & $20(54.1)$ & $25(37.9)$ & \\
\hline Median ICU LOS (days) & $12(5-22)$ & $7(5-13)$ & $17(6-35)$ & 0.005 \\
\hline Median hospital LOS (days) & $20(9-45)$ & $12(10-18)$ & $30.5(9-61)$ & 0.002 \\
\hline Mortality & $16(15.5)$ & $3(8.1)$ & $13(19.7)$ & 0.119 \\
\hline
\end{tabular}

Values are presented as number (\%) or median (IR).

TDI: traumatic diaphragmatic injury, IR: interquartile range, GCS: Glasgow coma scale, RTS: revised trauma score, ISS: injury severity score, ICU: intensive care unit, LOS: length of stay. 
most common cause of blunt injuries (43 cases). The location of the injuries did not show a statistically significant difference between groups. The median length of the diaphragmatic injury was $7 \mathrm{~cm}$ in the blunt injury group and $4 \mathrm{~cm}$ in the penetrating injury group, which was a significant difference $(p<0.001)$.

At the time of arrival at the emergency center, the majority of patients with penetrating injuries showed a GCS score of 14 or above, while a higher proportion of patients with blunt injuries showed a GCS score of 8 or lower. This difference was statistically significant $(p=0.005)$. The median RTS score, which is used to physiologically categorize trauma patients based on their early vital signs, was 7.40 and 6.51 in the two groups, respectively, and an analysis of the IR showed a significantly wider distribution of RTS in the blunt injury group ( $p=0.001$ ). A higher proportion of patients in the blunt injury group had an ISS score of 15 or higher, indicating major trauma. This finding was statistically significant $(p=0.016)$.

An analysis of the time of diagnosis indicated that 45 patients were incidentally diagnosed with TDI during surgery. In the blunt injury group, many patients were diagnosed prior to surgery via modalities such as chest $\mathrm{X}$-rays and chest computed tomography (CT), but this difference between the groups was not statistically significant $(p=0.200)$. The median durations of intensive care unit stay and hospitalization were 17 days and 30.5 days, respectively, in the blunt injury group, which were significantly longer than the durations of 7 days and 12 days in the penetrating injury group $(p=0.005, p=0.002$, respectively). The blunt injury group (19.7\%) had a higher mortality rate than the penetrating injury group (8.1\%), although the difference was not statistically significant ( $p=0.119$ ).

No significant differences were found in early vital signs and arterial blood gas analysis (ABGA) results according to the mechanism of injury (Table 2). Thoracic vessel, esophagus, and adrenal gland injuries occurred more frequently in the penetrating injury group, although this tendency was not statistically significant ( $p=0.260$, $p=0.180, p=0.180$, respectively). Liver injuries were significantly more common in the penetrating injury group ( $p=0.007)$. Other accompanying organ injuries were more frequent in the blunt injury group, but significant differences were only found for rib fractures $(p=0.009)$, pelvic injuries $(p<0.001)$, brain injuries $(p=0.005)$, spinal injuries $(p=0.005)$, and extremity fractures $(p<0.001)$ (Table 3$)$.

All patients with TDI were assessed for the presence of respiratory compromise and to determine the location of and reason for the procedure conducted in the emergency center (Table 4). Through an investigation of $\mathrm{PCO}_{2}$ and $\mathrm{SaO}_{2}$ on the initial ABGA, and saturation on pulse oximetry, it was found that respiratory compromise occurred in $16.2 \%$ of patients with a penetrating injury and in $48.5 \%$ of those with a blunt injury, which was a statistically significant difference $(p<0.001)$. After categorizing 66 blunt

Table 2. Initial hemodynamic, respiratory, and physiological variables of 103 TDI patients

\begin{tabular}{|lccc|}
\hline & Total & Penetrating TDI & Blunt TDI \\
\hline $\mathrm{SBP}(\mathrm{mmHg})$ & $110(90-130)$ & $109(90-120)$ & $110(90-130)$ \\
$\mathrm{DBP}(\mathrm{mmHg})$ & $70(60-80)$ & $70(60-80)$ & $70(60-80)$ \\
$\mathrm{HR}$ (beats/min) & $99(84-112)$ & $98(88-110)$ & $100(82-113)$ \\
$\mathrm{RR}($ breaths/min) & $20(20-26)$ & $21(20-25)$ & $20(20-27)$ \\
$\mathrm{pH}$ & $7.33(7.28-7.38)$ & $7.31(7.29-7.38)$ & $7.33(7.26-7.39)$ \\
PCO $(\mathrm{mmHg})$ & $38(32-43)$ & $35(31-43)$ & $38(34-43)$ \\
$\mathrm{HCO}(\mathrm{mmol} / \mathrm{L})$ & $19.8(16.4-22.7)$ & $19.7(16.1-22.1)$ & $20.35(16.6-22.7)$ \\
$\mathrm{Lactate}(\mathrm{mmol} / \mathrm{L})$ & $3(1.8-4.7)$ & $3.1(1.9-5.8)$ & $3(1.7-4.7)$ \\
$\mathrm{BE}(\mathrm{mmol} / \mathrm{L})$ & $-5.3(-9.3$ to -2.5$)$ & $-5.1(-9.3$ to -3.3$)$ & $-5.4(-9.1$ to -2.5$)$ \\
\hline
\end{tabular}

Values are presented as median $(\mathbb{R})$.

TDI: traumatic diaphragmatic injury, IR: interquartile range, SBP: systolic blood pressure, DBP: diastolic blood pressure, HR: heart rate, RR: respiratory rate, BE: base excess 
trauma patients with respiratory compromise according to the cause of injury (brain injury, hypovolemia, or intrathoracic problems), we found that intrathoracic problems were the most common cause.

The proportion of intubated patients was also significantly higher in the blunt injury group, as $18.9 \%$ of patients with penetrating injuries and $57.6 \%$ of those with blunt injuries required intubation $(p<0.001)$. A decreased level of consciousness was the most common reason for early intubation in 29 patients, of whom 26 had experienced blunt injuries. In this study, early intubation was defined as endotracheal intubation performed in the emergency department at the initial visit regardless of time. In the penetrating injury group, intubation was performed due to hypovolemic shock in $28.6 \%$ of the intubated patients, which was a significantly higher proportion than in the blunt injury group $(7.9 \%, p=0.016)$.

All patients with TDI were categorized according to the mechanism and location of organ herniation (Table 5). The stomach was the only organ that showed statistically significant differences in terms of both mechanism and location. Stomach herniation was more common in patients with blunt injuries (16 patients) than in those with penetration injuries $(p=0.005)$ and more frequently occurred on the left side (16 patients) than on the right side $(p=0.006)$. Herniation of the large bowel $(p=0.009)$ and omentum $(p=0.018)$ more frequently developed on the left side, but a lack of herniation was more frequently observed on the right side $(p<0.001)$.

As shown in Table 6, emergency surgery (performed within 6 hours of the injury) was more frequent in patients with penetrating injuries (14 patients) than in those with blunt injuries. Delayed surgery (after 6 hours of injury) was more frequent in patients with blunt injuries (55 patients) than in those with penetrating injuries $(p=0.016)$. The thoracic approach and abdominal

Table 3. Accompanying injuries in TDI patients

\begin{tabular}{|c|c|c|c|c|}
\hline & Total $(n=103)$ & Penetrating $(n=37)$ & Blunt $(n=66)$ & $p$-value \\
\hline Thoracic vessel injury & $3(2.9)$ & $2(5.4)$ & $1(1.5)$ & 0.260 \\
\hline Pulmonary injury & $23(22.3)$ & $7(18.9)$ & $16(24.2)$ & 0.534 \\
\hline Rib fracture & $30(29.1)$ & $5(13.5)$ & $25(37.9)$ & 0.009 \\
\hline Pneumothorax & $26(25.2)$ & $9(24.3)$ & $17(25.8)$ & 0.872 \\
\hline Cardiac injury & $4(3.9)$ & $2(5.4)$ & $2(3.0)$ & 0.549 \\
\hline Hemothorax & $53(51.5)$ & $19(51.4)$ & $34(51.5)$ & 0.987 \\
\hline Esophagus & $1(1.0)$ & $1(2.7)$ & $0(0.0)$ & 0.180 \\
\hline Abdominal vessel injury & $5(4.9)$ & $1(2.7)$ & $4(6.1)$ & 0.447 \\
\hline Liver & $26(25.2)$ & $15(40.5)$ & $11(16.7)$ & 0.007 \\
\hline Spleen & $19(18.5)$ & $6(16.2)$ & $13(19.7)$ & 0.662 \\
\hline Stomach & $6(5.8)$ & $3(8.1)$ & $3(4.6)$ & 0.459 \\
\hline Pancreas & $2(1.9)$ & $0(0.0)$ & $2(3.0)$ & 0.285 \\
\hline Kidney & $3(2.9)$ & $0(0.0)$ & $3(4.6)$ & 0.188 \\
\hline Bowel & $10(9.7)$ & $4(10.8)$ & $6(9.1)$ & 0.777 \\
\hline Adrenal gland & $1(1.0)$ & $1(2.7)$ & $0(0.0)$ & 0.180 \\
\hline Pelvis & $21(20.4)$ & $0(0.0)$ & $21(31.8)$ & $<0.001$ \\
\hline Brain & $17(16.5)$ & $1(2.7)$ & $16(24.2)$ & 0.005 \\
\hline Spine & $17(16.5)$ & $1(2.7)$ & $16(24.2)$ & 0.005 \\
\hline Extremities fracture & $25(24.3)$ & $1(2.7)$ & $24(36.4)$ & $<0.001$ \\
\hline
\end{tabular}

Values are presented as number (\%).

TDI: traumatic diaphragmatic injury. 
approach were chosen in 49 and 48 patients, respectively, and this difference was not statistically significant $(p=0.982)$.

\section{DISCUSSION}

TDI is no longer considered to be a rare condition, especially given its increased incidence due to traffic accidents, industrial accidents, and acts of violence. With advancements in diagnostic techniques and medical devices that enable early diagnosis, this condition can be easily detected. Therefore, it is important to make an early diagnosis by performing thorough testing of patients at the emergency department, where various diagnostic approaches are applied to assess patients in the early stages of trauma [7].

Although studies have reported varying results, TDI occurs in $7 \%$ of patients with blunt chest injury, and its incidence according to autopsy results of patients who died due to severe multi-organ damage was $5.2-17 \%[8,9]$.
Wise et al. [10] reported that TDI occurred primarily in individuals aged between 10 and 40 years, with a 4:1 maleto-female ratio. Griswold et al. [11] reported a mean age of 23 years and a 4.5:1 male-to-female ratio. However, this study showed a higher median age of incidence (56 years). Approximately $73.8 \%$ of the enrolled patients were male, which may reflect the fact that males more frequently experience traffic accidents, industrial accidents, and penetrating chest injuries.

TDI was first reported in 1,541, and subsequently, several studies have reported that $75 \%$ of TDI cases occurred in patients with blunt trauma, and $90 \%$ occurred on the left side $[12,13]$. The location of damage is predominantly on the left side in both blunt and penetrating injuries [14], because the perpetrators of penetrating injuries are usually right-handed. Furthermore, the left side is structurally weaker in cases of blunt injuries, because it is the site of embryological coalescence. The right diaphragm is less prone to damage, as it is protected by the liver and its ligaments are connected to the adjacent organs, as well as

Table 4. Procedures performed in TDI patients in the emergency department

\begin{tabular}{|c|c|c|c|c|}
\hline & Total $(n=103)$ & Penetrating $(n=37)$ & Blunt $(n=66)$ & $p$-value \\
\hline Respiratory compromise & $38(36.9)$ & $6(16.2)$ & $32(48.5)$ & $<0.001$ \\
\hline Intubation & $45(43.7)$ & $7(18.9)$ & 38 (57.6) & $<0.001$ \\
\hline Reason for intubation & & & & 0.016 \\
\hline For hypovolemic shock & $5(11.1)$ & $2(28.6)$ & $3(7.9)$ & \\
\hline For altered Mentality & $29(64.4)$ & $3(42.9)$ & $26(68.4)$ & \\
\hline For respiratory distress & $8(17.8)$ & $0(0.0)$ & $8(21.1)$ & \\
\hline For another reason & $3(6.7)$ & $2(28.6)$ & $1(2.6)$ & \\
\hline Levin tube insertion & $71(68.9)$ & $23(62.2)$ & $48(72.7)$ & 0.266 \\
\hline Chest tube insertion & $54(52.4)$ & $21(56.8)$ & $33(50.0)$ & 0.510 \\
\hline Site of insertion & & & & 0.576 \\
\hline Right & $18(33.3)$ & $6(28.6)$ & $12(36.4)$ & \\
\hline Left & $35(64.8)$ & $15(71.4)$ & $20(60.6)$ & \\
\hline Both & $1(1.9)$ & $0(0.0)$ & $1(3.0)$ & \\
\hline Reason for insertion & & & & 0.478 \\
\hline Hemothorax & $28(51.9)$ & $12(57.1)$ & $16(48.5)$ & \\
\hline Pneumothorax & $2(3.7)$ & $0(0.0)$ & $2(6.1)$ & \\
\hline Hemopneumothorax & $24(44.4)$ & $9(42.9)$ & $15(45.5)$ & \\
\hline
\end{tabular}

Values are presented as number (\%).

TDI: traumatic diaphragmatic injury. 
due to the plugging effect $[14,15]$. However, the difference in incidence between the left and the right side is gradually decreasing, with the proportion of right-sided injuries increasing to approximately $30-40 \%$ in recent years [16]. This is probably due to the increased incidence of severe blunt trauma associated with road traffic accidents, with a resultant increase in right-sided injuries despite the greater structural strength of the right side, as well as due to the higher survival rate of multiple trauma patients resulting from advances in the emergency medicine system, medical technology, and diagnostic accuracy $[15,17]$. In this study, $66 \%$ of cases involved blunt injuries, with causes such as road traffic accidents and falls, $67 \%$ of which occurred on the left side. However, the proportion of right-sided injuries was also fairly high, at $31.1 \%$. Ex- cluding two patients with bilateral injuries and dividing the study period into its first and second halves, with 2010 as the midpoint, 10 of the 50 TDI patients between 2000 and 2009 had a right-sided injury (20\%). In contrast, in 2010-2018, 22 of 51 patients had a right-sided injury (43.1\%), showing a two-fold increase compared with the previous period.

The symptoms of TDI vary greatly, and it is affected more strongly than other types of diaphragmatic injuries by other accompanying injuries. Although TDI has no distinctive diagnosable symptoms or signs, failure to detect damage caused by TDI can cause severe complications $[7,13]$. Therefore, even if a diaphragmatic injury is not diagnosed radiologically, an active investigation and surveillance for damage is necessary, if suspected based

Table 5. Herniated structures in 103 TDI patients

\begin{tabular}{|c|c|c|c|c|c|c|c|}
\hline \multirow{2}{*}{ Herniated structure } & \multicolumn{2}{|c|}{ Mechanism of injury } & \multirow{2}{*}{$p$-value } & \multicolumn{3}{|c|}{ Side of injury } & \multirow{2}{*}{$p$-value } \\
\hline & Penetrating & Blunt & & Right & Left & Bilateral & \\
\hline Liver & $0(0.0)$ & $3(4.6)$ & 0.188 & $0(0.0)$ & $3(4.4)$ & $0(0.0)$ & 0.467 \\
\hline Spleen & $0(0.0)$ & $4(6.1)$ & 0.127 & $0(0.0)$ & $4(5.8)$ & $0(0.0)$ & 0.359 \\
\hline Stomach & $1(2.7)$ & $16(24.2)$ & 0.005 & $0(0.0)$ & $16(23.2)$ & $1(50.0)$ & 0.006 \\
\hline Large bowel & $1(2.7)$ & $5(7.6)$ & 0.311 & $0(0.0)$ & $5(7.3)$ & $1(50.0)$ & 0.009 \\
\hline Small bowel & $0(0.0)$ & $5(7.6)$ & 0.086 & $0(0.0)$ & $5(7.3)$ & $0(0.0)$ & 0.274 \\
\hline Omentum & $6(16.2)$ & $8(12.1)$ & 0.561 & $0(0.0)$ & $14(20.3)$ & $0(0.0)$ & 0.018 \\
\hline No herniation ${ }^{a}$ & $29(78.4)$ & $42(64.6)$ & 0.146 & $31(96.9)$ & $39(57.4)$ & $1(50.0)$ & $<0.001$ \\
\hline
\end{tabular}

Values are presented as number (\%).

TDI: traumatic diaphragmatic injury.

aAll values, except those for no herniation, could be duplicated.

Table 6. Operative approach, time, and method in 103 TDI patients

\begin{tabular}{|c|c|c|c|c|}
\hline & Total $(n=103)$ & Penetrating $(n=37)$ & Blunt $(n=66)$ & $p$-value \\
\hline Time interval between injury and operation & & & & 0.016 \\
\hline$<6$ hours & $25(24.8)$ & $14(37.8)$ & $11(16.7)$ & \\
\hline $6+$ hours & $78(75.7)$ & $23(62.2)$ & $55(83.3)$ & \\
\hline No operation & $0(0.0)$ & $0(0.0)$ & $0(0.0)$ & \\
\hline Operative approach & & & & 0.982 \\
\hline Thoracic & $49(47.6)$ & $18(48.7)$ & $31(47.0)$ & \\
\hline Abdominal & $48(46.6)$ & $17(46.0)$ & $31(47.0)$ & \\
\hline Thoracic and abdominal & $6(5.8)$ & $2(5.4)$ & $4(6.1)$ & \\
\hline
\end{tabular}

Values are presented as number (\%).

TDI: traumatic diaphragmatic injury. 
on the mechanism of injury. No standard test exists for diagnosing diaphragmatic injuries, and the preoperative diagnosis rate is low despite the use of multiple modalities such as chest X-rays, chest CT, and focused abdominal sonography for trauma. Approximately $65 \%$ of TDI cases are diagnosed intraoperatively and, sometimes even decades later $[12,18]$. Simple chest X-rays are the most common differential diagnostic technique, but have low sensitivity and specificity [19]. On the contrary, high-resolution, multi-slice CT of the chest has recently shown a higher accuracy in the diagnosis of TDI and is performed routinely in blunt trauma patients. However, despite the increasingly widespread use of CT, many patients with TDI are not diagnosed at the initial evaluation [20]. In this study, preoperative diagnoses using chest X-rays and chest CT were more commonly performed in patients with blunt injuries (43.9\%) than in those with penetrating injuries (27.0\%). This was probably because patients with penetrating injuries tend to undergo emergency surgery without preoperative investigations. In contrast, as blunt injuries tend to be accompanied by multiple areas of complex damage, patients tend to undergo a radiological evaluation prior to surgery, resulting in a higher preoperative diagnosis rate. For this reason, the time to surgery in cases of blunt injuries is likely to be longer, as confirmed by the finding that the proportion of patients who underwent emergency surgery within 6 hours of injury was lower in patients with blunt injuries (16.7\%) than in patients with penetrating injuries (37.8\%).

TDI manifests along a spectrum based on the mechanism of injury. Penetrating injuries can cause small defects that may not result in organ herniation or defects large enough to cause abdominal organs to herniate into the thoracic cavity. However, the rapid increase in intra-abdominal pressure in blunt injuries tends to cause large tears along the central tendon of the diaphragm, and organ herniation occurs more easily [21-23]. In such cases, pressure is known to be transferred in a uniform radial pattern according to Pascal's law. A previous study reported that the right side of the diaphragm is protected by buffering organs such as the liver and heart, and is therefore less prone to damage than the left side $[24,25]$. In this study, the incidence of organ herniation was significantly higher in patients with blunt injuries, with $78.4 \%$ and $64.6 \%$ of patients in the penetrating and blunt injury groups not showing organ herniation, respectively $(p<0.001)$. Approximately $96.9 \%$ and $57.4 \%$ of patients did not show herniation on the right and left side of the diaphragm, respectively, reflecting a higher incidence of organ herniation on the left side (Table 5). An interesting finding in this study was liver herniation in three patients, all of whom showed left-sided herniation due to blunt injury. This finding provides empirical support for the proposal that in order for a large organ such as the liver to be herniated, a large tear caused by a blunt injury must occur, and this mechanism is more likely to cause herniation on the left side, which is weaker.

The median size of the damaged area was significantly larger in blunt injuries $(7 \mathrm{~cm})$ than in penetrating injuries $(4 \mathrm{~cm})(p<0.001)$. Ebert et al. [26] reported that diaphragmatic injuries occur more frequently after thoracic trauma than after abdominal trauma and that rib fracture is

Table 7. Risk factors for severe injury in univariate and multivariate analyses

\begin{tabular}{|c|c|c|c|c|c|}
\hline \multirow{2}{*}{ Variable } & & \multicolumn{2}{|c|}{ Unadjusted } & \multicolumn{2}{|c|}{ Adjusted } \\
\hline & & OR & $95 \% \mathrm{Cl}$ & $\mathrm{OR}^{\mathrm{a}}$ & $95 \% \mathrm{Cl}$ \\
\hline Mechanism of injury & Blunt & 3.04 & $1.20-7.70$ & 3.57 & $1.23-10.33$ \\
\hline Sex & Male & 0.53 & $0.20-1.41$ & - & - \\
\hline Size of diaphragmatic injury (cm) & & 1.13 & $0.99-1.29$ & - & - \\
\hline Respiratory compromise & & 36.24 & 4.25-309.27 & 42.0 & $4.63-380.73$ \\
\hline \multirow[t]{2}{*}{ Initial GCS } & Moderate (9-13) & 3.27 & 3.27 & - & - \\
\hline & Severe (3-8) & 4.43 & $0.94-20.81$ & & \\
\hline
\end{tabular}

OR: odds ratio, Cl: confidence interval, GCS: Glasgow coma scale.

a ORs were adjusted for the mechanism of injury and respiratory compromise. Other variables were removed by the method of backward elimination. 
often associated with and accompanied by diaphragm injury. Furthermore, thoracic injury was the most common accompanying injury (hemothorax, rib fracture, pneumothorax, pulmonary contusion, pericardial tear, and thoracic aorta injury). Other accompanying injuries included abdominal organ injury (liver tearing and spleen, colon, small intestine, abdominal aorta, and kidney damage), limb fracture, hip fracture, head trauma, and spine injury. Karmy-Jones and Jurkovich [27] reported that diaphragmatic injuries in severe blunt trauma were often accompanied by damage to the thoracoabdominal cavity, most often caused by rib fracture and hemopneumothorax, followed by spleen rupture, liver rupture, intestinal rupture, brain damage, and other fractures. In this study, these injuries occurred more frequently in blunt injuries, with the exception of thoracic aorta, liver, and adrenal injuries.

Dunham et al. [28] reported that the rate of endotracheal intubation in trauma centers reached up to $24.5 \%$. In this study, 45 patients (43.7\%) underwent endotracheal intubation in the emergency department. This value is higher than the previously reported rate of intubation. In 29 of these 45 patients, intubation was performed due to changes in mental status, and 26 of those patients sustained blunt injuries. This is probably associated with the fact that blunt injuries are often accompanied by other types of organ injuries, including brain injury. Approximately $28.6 \%$ and $7.9 \%$ of penetrating injury and blunt injury patients, respectively, underwent endotracheal intubation due to hypovolemic shock; this was significantly more common in the penetrating injury group ( $p=0.016$ ), probably due to the large amount of blood loss after stab wounds. This finding is consistent with our hypothesis, according to which patients with TDI due to a blunt injury would have a poorer prognosis than those with TDI due to a penetrating injury. In the assessment of patients' early mental status at the time of presentation to the emergency department using the GCS score, $28.8 \%$ and $5.4 \%$ of patients with blunt and penetrating injuries, respectively, showed a severely decreased GCS score of 3-8. Jung et al. [29] reported that the ISS is the most widely used anatomical scoring system due to its close correlation with the mortality rate and that a score of 15 or higher indicates major or severe trauma. In this study, $83.3 \%$ of patients with blunt injuries and $62.2 \%$ of patients with penetrating injuries had an ISS of 15 or above; furthermore, the blunt injury group (19.7\%) had a higher likelihood of mortality than the penetrating injury group $(8.1 \%)$. In a multivariate analysis, Watkins et al. [30] reported that the Acute Physiology and Chronic Health Evaluation II score, ISS, presence of a blunt injury, pulmonary contusion, massive blood transfusion, and flail chest were prognostic factors that could predict the occurrence of acute respiratory distress syndrome after a traumatic injury.

In our multivariate logistic regression analysis (Table 7), the severity of TDI was higher 3.57-fold higher in the blunt injury group than in the penetrating injury group (odds ratio [OR]: $3.57,95 \%$ confidence interval [CI]: 1.23-10.33). Furthermore, the risk of severe TDI was about 42 -fold higher in patients with respiratory compromise (OR: 42.0, 95\% CI: 4.63-380.73). In contrast, sex, size of the damaged area, and the initial GCS had no impact on severity.

The limitations of this study include its small sample size, as it targeted TDI patients from a single emergency medical center. Although Gachon University Gil Medical Center is a trauma center, the number of patients over the past 19 years was relatively small. Moreover, this study is retrospective in nature, which is an especially relevant limitation considering the missing paper records from before the implementation of an electronic medical record system.

\section{CONCLUSION}

With advances in society and improvements in the healthcare environment, the incidence of TDI and its diagnosis are increasing. In the emergency setting, TDI must be recognized in patients with blunt injury and/or respiratory compromise and should be managed proactively. Early implementation of an appropriate management strategy would improve patients' prognosis, regardless of the mechanism of injury. A future multi-center, prospective study is warranted to determine the survival rate and neurological outcome of patients with TDI. 


\section{REFERENCES}

1. Rosati C. Acute traumatic injury of the diaphragm. Chest Surg Clin N Am 1998;8:371-9.

2. Scharff JR, Naunheim KS. Traumatic diaphragmatic injuries. Thorac Surg Clin 2007;17:81-5.

3. Meyers BF, McCabe CJ. Traumatic diaphragmatic hernia. Occult marker of serious injury. Ann Surg 1993;218:783-90.

4. Rizoli SB, Brenneman FD, Boulanger BR, Maggisano R. Blunt diaphragmatic and thoracic aortic rupture: an emerging injury complex. Ann Thorac Surg 1994;58:1404-8.

5. Fair KA, Gordon NT, Barbosa RR, Rowell SE, Watters JM, Schreiber MA. Traumatic diaphragmatic injury in the American College of Surgeons National Trauma Data Bank: a new examination of a rare diagnosis. Am J Surg 2015;209:864-9.

6. Lopez PP, Arango J, Gallup TM, Cohn SM, Myers J, Corneille M, et al. Diaphragmatic injuries: what has changed over a 20 -year period? Am Surg 2010;76:512-6.

7. Kim Y. A clinical analysis of traumatic diaphragmatic injury. J Korean Soc Traumatol 2004;17:67-73.

8. Beal SL, Mckennan M. Blunt diaphragm rupture. A morbid injury. Arch Surg 1988:123;828-32.

9. Estrera AS, Platt MR, Mills LJ. Traumatic injuries of the diaphragm. Chest 1979;75:306-13.

10. Wise L, Connors J, Hwang YH, Anderson C. Traumatic injuries to the diaphragm. J Trauma 1973;13:946-50.

11. Griswold FW, Worden HE, Gardner RJ. Acute diaphragmatic rupture caused by blunt trauma. Am J Surg 1972;124:359-62.

12. Shah R, Sabanathan S, Mearns AJ, Choudhury AK. Traumatic rupture of diaphragm. Ann Thorac Surg 1995;60:1444-9.

13. Morgan BS, Watcyn-Jones T, Garner JP. Traumatic diaphragmatic injury. J R Army Med Corps 2012;156:139-44.

14. de la Rocha AG, Creel RJ, Mulligan GW, Burns CM. Diaphragmatic rupture due to blunt abdominal trauma. Surg Gynecol Obstet 1982;154:175-80.

15. Estrera AS, Landay MJ, McClelland RN. Blunt traumatic rupture of the right hemidiaphragm: experience in 12 patients. Ann Thorac Surg 1985;39:525-30.
16. Drews JA, Mercer EC, Benfield JR. Acute diaphragmatic injuries. Ann Thorac Surg 1973;16:67-78.

17. Düzgün AP, Ozmen MM, Saylam B, Co kun F. Factors influencing mortality in traumatic ruptures of diaphragm. Ulus Travma Acil Cerrahi Derg 2008;14:132-8.

18. Ozgüç H, Akköse S, Sen G, Bulut M, Kaya E. Factors affecting mortality and morbidity after traumatic diaphragmatic injury. Surgery Today 2007;37:1042-6.

19. Guth AA, Pachter HL, Kim U. Pitfalls in the diagnosis of blunt diaphragmatic injury. Am J Surg 1995;170:5-9.

20. Haciibrahimoglu G, Solak O, Olcmen A, Bedirhan MA, Solmazer N, Gurses A. Management of traumatic diaphragmatic rupture. Surg Today 2004;34:111-4.

21. Adegboye VO, Ladipo JK, Adebo OA, Brimmo AI. Diaphragmatic injuries. Afr J Med Med Sci 2002;31:149-53.

22. Matsevych OY. Blunt diaphragmatic rupture: four year's experience. Hernia 2008;12:73-8.

23. Shehata SM, Shabaan BS. Diaphragmatic injuries in children after blunt abdominal trauma. J Pediatr Surg 2006;41:1727-31.

24. Van Vugt AB, Schoots FJ. Acute diaphragmatic rupture due to blunt trauma: a retrospective analysis. J Trauma 1989;29:683-6.

25. Andrus $\mathrm{CH}$, Morton JH. Rupture of the diaphragm after blunt trauma. Am J Surg 1970;119:686-93.

26. Ebert PA, Gaertner RA, Zuidema GD. Traumatic diaphragmatic hernia. Surg Gynecol Obstet 1967;125:59-65.

27. Karmy-Jones R, Jurkovich GJ. Blunt chest trauma. Curr Probl Surg 2004;41:211-380.

28. Dunham CM, Barraco RD, Clark DE, Daley BJ, Davis FE 3rd, Gibbs MA, et al. Guidelines for emergency tracheal intubation immediately after traumatic injury. J Trauma 2003;55:162-79.

29. Jung K, Lee CJ, Kim J. Injury severity scoring system for trauma patients and trauma outcomes research in Korea. J Acute Care Surg 2016;6:11-7.

30. Watkins TR, Nathens AB, Cooke CR, Psaty BM, Maier RV, Cuschieri J, et al. Acute respiratory distress syndrome after trauma: development and validation of a predictive model. Crit Care Med 2012;40:2295-303. 